\title{
APROPRIAÇÕES DAS MÍDIAS DIGITAIS NA FORMAÇÃO CONCEITUAL E NA CONSTRUÇÃO CONJUNTA DE SIGNIFICADOS NA UNIVERSIDADE
}

\author{
Dirce Aparecida Foletto de MORAES ${ }^{1}$ \\ Claudia Maria de LIMA ${ }^{2}$
}

\begin{abstract}
Resumo
Este artigo almeja compreender as formas de apropriações e de uso das mídias digitais nas práticas acadêmicas de estudantes universitários para aprender. Com abordagem qualitativa, de caráter exploratório e com características da pesquisa-intervenção, a pesquisa foi realizada junto a uma turma de 41 estudantes ingressantes no curso de Pedagogia, que participaram de uma proposta didática com o propósito de desenvolver uma postura ativa e autônoma na busca pelo conhecimento científico. A teoria da cognição distribuída foi tomada como unidade de análise dos dados coletados por meio de observação participante, de diálogos nas redes sociais e de análise documental das produções nos ambientes colaborativos e tratados sob a ótica da análise de conteúdos. Os dados revelam que os jovens se apropriaram das mídias digitais de variadas formas e para diversos fins. Com isso, evidenciaram-se duas grandes categorias: como mediadoras na formação conceitual, por meio do diálogo, dos confrontos cognitivos e do compartilhamento, e como ferramenta de construção conjunta de significados, por meio da parceria intelectual, da participação, da colaboração e da ajuda mútua. O estudo indica, ainda, que, ao vivenciar experiências desafiadoras e diferenciadas com as mídias digitais, os estudantes se apropriam destas como mediadoras dos processos formativos, o que favorece a formação conceitual na universidade.
\end{abstract}

Palavras-chave: Aprendizagem. Didática. Formação de Conceitos. Mediação. Mídias Digitais.

\footnotetext{
${ }^{1}$ Doutora em Educação. Docente do Programa do Pós-Graduação em Educação da Universidade Estadual de Londrina - UEL. ORCID: http://orcid.org/0000-0002-1392-1605.

E-mail: dircemoraes@uel.br.

${ }^{2}$ Doutora em Educação. Docente do Programa de Pós-Graduação em Educação da Unesp/Presidente Prudente ORCID: http://orcid.org/0000-0003-4979-5070.

E-mail: claudiamarialima@uol.com.br.
} 


\title{
APPROPRIATIONS OF DIGITAL MEDIA IN CONCEPTUAL FORMATION AND JOINT CONSTRUCTION OF MEANINGS IN UNIVERSITY
}

\author{
Dirce Aparecida Foletto de MORAES \\ Claudia Maria de LIMA
}

\begin{abstract}
This paper aims to understand the ways of appropriation and use of digital media in the academic practices of university students. With a qualitative approach, an exploratory form and characteristics of the intervention research, the search was made with a group of 41 students of the Pedagogy course that participated in a didactic proposal of developing an active and autonomous position in the search for scientific knowledge. Distributed cognition theory was taken as a unit of analysis of the data collected through participant observation, dialogues in social networks and documentary analysis of the productions in the collaborative environments and treated from the perspective of content analysis. The data show that young people have appropriated digital media in different ways and for different purposes. Thus, two main categories emerged: as a mediator in conceptual formation through dialogue, cognitive confrontation and sharing and as a tool for the joint construction of meanings through intellectual partnership, collaboration and mutual aid. The study also emphasizes that when experiencing challenging and differentiated experiences with digital media, students appropriate these media as mediators of the training processes, and this benefits conceptual training at the university.
\end{abstract}

Keywords: Learning. Didactics, Conceptual Formation. Mediation. Digital Media. 


\title{
APROPIACIONES DE LOS MEDIOS DIGITALES EN LA FORMACIÓN CONCEPTUAL Y CONSTRUCCIÓN CONJUNTA DE SIGNIFICADOS EN LA UNIVERSIDAD
}

Dirce Aparecida Foletto de MORAES

Claudia Maria de LIMA

\begin{abstract}
Resumen
Este artículo tiene como objetivo comprender las formas de apropiación y de uso de los medios digitales en las prácticas académicas de los estudiantes universitarios. Con un enfoque cualitativo, carácter exploratorio y características de investigación de intervención, el estudio se realizó con un grupo de 41 estudiantes ingresando al curso de Pedagogía quienes participaron de una propuesta didáctica con el fin de desarrollar una postura activa y autónoma en la búsqueda del conocimiento científico. La teoría de la cognición distribuida fue tomada como unidad de análisis de datos, recolectados a través de la observación participante, de diálogos en redes sociales y de análisis documental de producciones en ambientes colaborativos y tratados desde la perspectiva del análisis de contenidos. Los datos revelan que los jóvenes se han apropiado de los medios digitales de diferentes formas y con diferentes propósitos. Como resultado, se evidenciaron dos amplias categorías: como mediadores en la formación conceptual, a través del diálogo, del enfrentamiento cognitivo y del compartir, y como herramienta para la construcción conjunta de significados, a través de la asociación intelectual, de la participación, de la colaboración y de la ayuda mutua. El estudio también revela que, al vivir experiencias desafiantes y diferenciadas con los medios digitales, los estudiantes se apropian de estos como mediadores de los procesos formativos, lo que favorece la formación conceptual en la universidad.
\end{abstract}

Palabras clave: Aprendizaje. Didáctica. Formación de Conceptos. Mediación. Medios Digitales. 


\section{Introdução}

No cenário sociocultural da atualidade, demarcado pela cibercultura, as pessoas estão apropriando-se das mídias digitais e, de alguma maneira, inserindo-as em suas atividades cotidianas para a realização de diferentes práticas, pois são muito atrativas e convidativas para vivenciar inúmeras tarefas e experiências, diferenciando-se das mídias anteriores por associar, em um único espaço, a comunicação e a informação, a interação, a atuação, o compartilhamento e o armazenamento de dados. Assim, trazem consigo a alternativa de autoria, a qual oportuniza que os sujeitos produzam conteúdo, e não apenas consumam aquilo que lhes é imposto.

Longe de uma visão reducionista, percebemos que os sujeitos vivem em um contexto em que as formas de organização social e cultural estão sendo reconfiguradas a partir das práticas de uso das mídias digitais e, com isso, expectativas de “[...] novos padrões, seletivos, de relações sociais que substituem as formas de interação humana territorialmente limitadas” (CASTELLS, 2003, p. 98) demarcam a sociedade atual e abrem espaço para várias formas de apropriações e de práticas sociais voltadas à criação de mídia na comunicação social (LANGE; ITO, 2010).

Além disso, nos ambientes em que as mídias digitais são as principais protagonistas, os jovens vão constituindo suas subjetividades na inter-relação com esses dispositivos, sem distinção entre o que acontece na web e fora dela, diversificando, inclusive, as formas de interação interpessoal, de identidade e de aprendizagem.

Os dados coletados na última edição da pesquisa TIC Domicílios, pela Comitê Gestor da Internet no Brasil [CGI.br] (CGI, 2020), trazem resultados expressivos para a compreensão do cenário contemporâneo. Em relação às formas de apropriação, a pesquisa revela que a função mais comum das mídias entre os jovens acima de 10 anos é a comunicação, sendo que 92\% dos usuários frisam o envio de mensagens instantâneas, 76\% apontam uso de redes sociais e 73\% mencionam chamadas de voz ou de vídeo.

A procura por informações é outro destaque na pesquisa, como uma das principais atividades realizadas na internet, considerando que $41 \%$ afirmam que fazem exercícios ou pesquisas escolares, 40\% estudam por conta própria e 12\% fazem cursos a distância.

Assistir a vídeo (74\%) e ouvir música (72\%) estão entre os principais hábitos dos jovens acima de 10 anos. No entanto, as apropriações voltadas para a produção de conteúdos ou para a criação de sites, de blogs e de páginas na internet ainda são pouco vivenciadas e praticadas pelos sujeitos.

As apropriações e as práticas de uso das mídias digitais estabelecidas pelos jovens, conforme exemplificam as pesquisas, vão configurando uma relação de proximidade e de afinidade, a ponto de 
tornarem-se inseparáveis de suas vidas, e, apesar de as apropriações mais comuns estarem voltadas para a comunicação, com percentual menor para a criação, as interfaces das mídias digitais permitem aos jovens práticas e oportunidades com as ferramentas de produção, de colaboração e de compartilhamento, favorecem o trabalho coletivo e abrem espaço para a aprendizagem mais interativa, colaborativa e autônoma, bem como promovem a troca de percepções e a distribuição da cognição.

Nesse sentido, entendemos a necessidade de organizar agendas educativas que considerem as formas de relação social, cultural e as produções de sentidos que esses sujeitos vêm desenvolvendo na contemporaneidade baseados na relação estabelecida com as mídias. Pea (1993) sublinha que as mídias digitais podem servir como ambientes experimentais capazes de abrir novas possibilidades para a cognição distribuída, por sua capacidade de mediação, de interação e de colaboração.

Ressaltamos que o conceito de cognição distribuída foi cunhado inicialmente por Edwin Hutchins (1995), contudo, para esta discussão, foram selecionados autores que tomam como base os preceitos da teoria histórico-cultural, com destaque para Salomon (1993), Cole e Engeström (1993), Pea (1993) e Brown et al. (1993), Karasavvidis (2002), dentre outros. Esses autores pautam seus trabalhos na influência do processo social, da mediação social e dos artefatos no desenvolvimento das funções psicológicas superiores.

Salomon (1993) explica que o termo “distribuído” se refere ao fato de que as capacidades mentais estão relacionadas a dois aspectos importantes: não se limitam a um único lócus, ou seja, não estão localizadas somente na cabeça do sujeito, mas se estendem e se concretizam "em um sistema que compreende um indivíduo e seus pares, professor ou ferramentas culturalmente fornecidos” (p. 112); e referem-se ao significado da palavra, a qual está relacionada à ideia de compartilhar, de trocar, sejam experiências, conhecimentos, tarefas ou mesmo uma herança cultural. Dessa forma, ocorre entre os sujeitos uma "parceria intelectual” na qual a cognição é compartilhada/distribuída por alguma forma de mediação. Segundo o autor, a cognição distribuída ocorre em situações em que as cognições são partilhadas entre os membros de uma equipe, na qual cada um traz suas bagagens e suas contribuições e é afetado pelas contribuições dos demais ou do artefato utilizado.

Assim, as pessoas, os artefatos, os ambientes e as tarefas executadas tornam-se parceiros cognitivos ao mediar os sujeitos em suas atividades. Para Pea (1993, p. 48), o "conhecimento é comumente construído socialmente, por meio de objetivos, esforços colaborativos ou por diálogos e desafios trazidos pelas diferenças de perspectiva de cada pessoa”. Nessa mesma perspectiva, Cole e Engeström (1993) esclarecem que a distribuição da cognição humana ocorre no meio cultural que 
envolve o sujeito, a comunidade, as regras, os artefatos, os objetivos e a divisão do trabalho, os quais acontecem no mundo social e no tempo, considerando o processo sócio-histórico dos sujeitos.

Tal teoria rompe a ideia de que a pessoa aprende sozinha e consolida a compreensão de que ela é uma construção social que se dá por meio da mediação e das interações entre humanos e não humanos. Entretanto, no tocante ao cenário educativo, as práticas ainda estão atreladas a um ensino unidirecional, anacrônico e individualizado, carente de inovações e de técnicas que alterem as práticas instituídas ou que sejam capazes de aproveitar o potencial transformador que as mídias digitais se propõem a oferecer. Conforme Lange e Ito (2010), o conhecimento exigido para as tarefas realizadas com as mídias digitais e as probabilidades de aprendizagem baseadas na colaboração em rede expressam grandes ensejos para a aprendizagem acadêmica e científica.

Diante dessa realidade, o objetivo que norteou o trabalho foi compreender as formas de apropriações e de uso das mídias digitais nas práticas acadêmicas de estudantes universitários para aprender. A metodologia de estudo envolveu uma intervenção didática para ensinar conceitos com uma turma de 41 estudantes do primeiro ano do curso de Pedagogia, em que estes vivenciaram cenários diferenciados em relação às formas de produção de conhecimento, consolidando-se como uma performance desafiadora, capaz de operar a serviço do desenvolvimento dos estudantes. Tal intervenção contemplou a utilização de diversas mídias, selecionadas pelos próprios estudantes, para a apropriação conceitual e a construção conjunta de significados.

Além de responder ao problema de investigação proposto, este estudo também visa contribuir com o entendimento de que a aprendizagem acadêmica não se limita à reprodução de conteúdos estanques em sala de aula, mas se refere a um processo mais amplo, que envolve a elaboração e a reelaboração conceitual e a produção em detrimento da reprodução. Nesse percurso, as mídias digitais podem ser aliadas, desde que seu uso favoreça diferentes descobertas formativas aos sujeitos.

\section{O Caminho Percorrido}

No que se refere ao objetivo proposto: compreender as formas de apropriações e de uso das mídias digitais nas práticas acadêmicas de estudantes universitários para aprender, este estudo constitui-se como qualitativo, com caráter exploratório e descritivo. Quanto aos procedimentos de investigação, possui características de uma pesquisa-intervenção, a qual é uma tendência das pesquisas participantes e não se trata apenas e tão somente de uma metodologia de pesquisa que prima pela elaboração de conhecimento, mas de "um dispositivo de intervenção no qual se afirme o ato político que toda investigação constitui” (ROCHA; AGUIAR, 2003, p. 67). 

significados na universidade

A natureza das intervenções foi pautada na mediação como eixo central do processo formativo assente em situações diversas desafiadoras de elaboração conceitual distanciadas daquelas já conhecidas e instituídas no meio acadêmico. Para tanto, pretendemos mudanças no comportamento, nas relações estabelecidas, no papel do professor e do aluno e no entendimento das ações pedagógicas e exercícios que privilegiaram o trabalho coletivo, a construção conjunta de significados, a participação dos estudantes em toda organização do trabalho e nas decisões em relação à organização didática.

Em consonância com a proposta, as mídias digitais entraram em cena para colaborar com o propósito de fornecer um trabalho diferenciado. Dessa maneira, foram selecionadas somente aquelas capazes de propiciar maior potencial mediador e uma gama de possibilidades de interação, de participação e de colaboração entre os jovens.

Neste estudo, apresentamos especificamente uma atividade prática desenvolvida pelos estudantes do primeiro ano do curso de Pedagogia, na disciplina de Educação e Tecnologia, intitulada Expotec ${ }^{3}$, a qual foi uma proposta dos próprios estudantes que surgiu em determinado momento do percurso letivo, quando os jovens foram questionados sobre a melhor forma de trabalhar um conceito, o qual fazia parte da ementa. Várias ideias afloraram, e a sugestão de realizar um estudo que culminasse em uma exposição para disseminar e compartilhar as aprendizagens adquiridas com a comunidade foi eleita pelo grupo, sendo que esta ultrapassou as formas de ensinar e de aprender presentes no cenário universitário e viabilizou aos estudantes uma aprendizagem que resultasse em algo significativo e produtivo.

O conceito trabalhado foi o de tecnologia, e a ideia de fazer uma exposição envolvendo as diferentes ferramentas, sua relação com a história e com a evolução da humanidade, o significado, as ambivalências e seu papel no contexto sociocultural decorreu do desejo de mobilizar a comunidade para refletir sobre o conceito da mesma forma como eles estavam fazendo e do desejo de ultrapassar os limites da sala de aula e vivenciar outras ações formativas. A partir de tal escolha, os jovens se organizaram em grupos de trabalho para estudar, planejar e organizar a exposição.

Durante o processo de planejamento e de organização para a exposição, não houve nenhuma imposição e tudo foi decidido no coletivo, ficando claro que todos tinham vez e voz nas decisões. Isso foi fundamental para que os estudantes se sentissem à vontade para opinar, sugerir e discordar e trabalhar coletivamente.

\footnotetext{
${ }^{3} \mathrm{O}$ nome da exposição foi escolhido pelos estudantes por meio de votação no grupo do Facebook.
} 
Para a concretização desse trabalho, houve uma preparação prévia com total autonomia dos estudantes e o acompanhamento de forma sistematizada para orientá-los no caminho para a apropriação dos conceitos e para que assumissem uma postura ativa e autônoma na busca pelo conhecimento científico e na execução do trabalho.

Em relação ao período de preparação, um primeiro encontro destinado ao planejamento sucedeu fora do horário de aula. Nessa reunião, o grupo iniciou o trabalho delineando o objetivo a ser atingido com a exposição, que ficou assim elaborado: mobilizar a comunidade para refletir sobre o conceito de tecnologia em suas vidas. A sequência da reunião envolveu a discussão de ideias sobre como poderiam realizar a exposição e eles definiram que a turma seria dividida em grupos para trabalhar as seguintes tecnologias: linguagem, relógio, calendário e meios de transporte, informação e comunicação, vestimentas, ferramentas e ambivalências.

A exposição foi planejada e realizada pelos estudantes de modo que os participantes não apenas assistissem à apresentação ou recebessem uma informação, mas que pudessem mediar e interagir com o conceito. Para isso, focalizaram a apropriação conceitual por meio de investigações, de leituras, de debates, de produção de conteúdos e de materiais subsidiários ao trabalho, tendo como suporte as mídias digitais.

Dentre os caminhos teóricos que a literatura oferece, optamos pela cognição distribuída como marco teórico desta pesquisa e das intervenções, pois está centrada nos processos mentais que ocorrem a partir da mediação e da interação entre vários sujeitos e os dispositivos tecnológicos na realização de uma determinada atividade ou na produção colaborativa do conhecimento. Na intervenção didática, essa teoria direcionou a proposta que envolveu a mediação em diferentes atividades e situações, como em ações coletivas, na participação colaborativa dos sujeitos e no entendimento e no uso dos artefatos como potencializadores dos processos formativos.

Nessa abordagem, a compreensão da distribuição da cognição ultrapassa a perspectiva material e limitada para dar espaço à dimensão essencialmente social, a qual envolve as mídias, as atividades, as pessoas e os contextos sociais e culturais. Isso significa que a distribuição da cognição não se dá unicamente entre artefatos e sujeitos, mas nas diversas situações da cultura, em um processo colaborativo e compartilhado.

Os dados coletados por meio de observação participante, dos diálogos nas redes sociais e da análise documental das produções nos espaços virtuais de compartilhamento foram analisados com apoio da técnica da Análise de Conteúdos (BARDIN, 1997), que consiste, segundo a autora, em tratar as informações seguindo um roteiro composto por três fases, sendo elas: Pré-análise, que 
compreende organização e seleção dos documentos a serem analisados, elaboração de objetivos e de indicadores que subsidiarão a interpretação final; Exploração do material, que diz respeito à escolha da unidade de registro e de contagem e seleção de categorias, quer dizer, é a transformação dos dados brutos em dados representativos; e Tratamento dos resultados, inferência e interpretações, que se refere à categorização dos dados. Nessa fase, o conteúdo é categorizado visando tornar os dados brutos significativamente válidos.

Da análise de conteúdo realizada, observamos duas categorias entendidas como formas de apropriação das mídias digitais pelos estudantes na atividade acadêmica realizada: como mediadoras na apropriação conceitual e como ferramentas na construção coletiva de significados.

\section{Marcas no Caminho Percorrido}

Os alunos se apropriaram das mídias digitais desde o princípio do trabalho. Primeiramente, para a escolha do nome da exposição, quando uma estudante sugeriu fazer uma enquete, no grupo do Facebook, solicitando sugestões dos colegas e votação. Depois, em vários momentos, para construções coletivas, elaboração conceitual e produção de conteúdo, os jovens privilegiaram as ferramentas de compartilhamento, como WhatsApp, Facebook, Blog, Google Drive e Lucidchart. Para a elaboração de material e a organização das atividades, utilizaram ferramentas como o Movie Maker, o Power point e o Prezi.

Importante destacar que a opção por trabalhar com essas ferramentas partiu diretamente dos grupos, e não da professora, o que demonstrou grande autonomia no desenvolvimento do trabalho e na construção conjunta de significados.

Os dados coletados assinalam que, dos oito grupos formados, seis optaram pelo WhatsApp e dois optaram pelo Facebook como espaço como espaço de diálogo, de trocas, de compartilhamento e de interação. Essas formas de apropriação indicam, como categoria, a mediação na apropriação conceitual. Para a teoria da cognição distribuída, os momentos de diálogo e de interação durante a realização de uma tarefa são oportunos para a mediação e a distribuição do conhecimento entre os sujeitos, e, quanto mais as pessoas participam e se envolvem, mais esse processo vai intensificandose (PEA, 1993; SALOMON, 1993; HERRERO; BROWN, 2010).

A seguir, relataremos um pouco do processo desenvolvido, iniciando com o grupo das ambivalências para exemplificar o processo de apropriação das mídias digitais. A escolha de utilizar uma mídia digital como mediadora foi feita quando as estudantes sentiram a necessidade de dialogar e de debater sobre os conceitos e os textos discutidos em sala com mais 
profundidade. Para isso, decidiram criar um grupo fechado na rede social Facebook. As estudantes fizeram uso do espaço para dialogar, confrontar ideias, compartilhar imagens e vídeos sobre o assunto. A seguir, alguns excertos:

Vamos ver se todos concordam, em fazermos por escrito as perguntas, lançando imagens boas e ruins, porque assim fica mais fácil a compreensão. Pensei isso porque da mesma forma que muitas de nós não sabíamos o que era ambivalência, algumas pessoas podem não entender (Aluna 10).

Estava pensando: seria interessante que o vídeo tivesse um narrador que explicasse a mensagem que queremos passar. Assim, aqueles que não compreendem bem os termos que vamos usar, terão mais facilidade de entender (Aluna 14).

Uma observação importante é que nessa relação de troca e de negociações o respeito foi um elemento presente, as ideias eram partilhadas, discutidas e só executadas quando todas as integrantes aprovavam. Como exemplo, podemos citar a situação na qual uma estudante inicia a produção do texto base para o vídeo no Google Drive com uma frase e uma imagem e, em seguida, um comentário provoca a negociação sobre como será o trabalho. As colegas participaram e ajudaram na construção. Abaixo, alguns fragmentos desse diálogo:

Seria mais ou menos assim? Uma imagem e a narração em cima? (Aluna 10).

Podemos colocar mais de uma imagem, dependendo do que abordarmos (Aluna 14).

Meninas, escrevi algo que poderíamos narrar... A respeito da parte boa da tecnologia. Seria interessante começar com o lado bom da tecnologia e depois falar do ruim... (Aluna 16).

O grupo das vestimentas igualmente fez um trabalho em que a interação, o compartilhamento e o diálogo foram categorias enfatizadas ao apropriarem-se das mídias digitais. A opção por realizar uma exposição sobre a vestimenta enquanto tecnologia foi do próprio grupo, e os objetivos, segundo as estudantes, eram mostrar a evolução e as diferenças das vestes entre os países, desde as primeiras vestimentas até a atualidade, e evidenciar a criação e a utilização das vestimentas, citando as necessidades e os costumes de cada sociedade.

Como não tinham muita certeza acerca de como fazer o trabalho, resolveram debater por meio do aplicativo Whatsapp e abrir um documento no Google Drive para esboçar algumas ideias. No início da conversa no Whatsapp, as estudantes ficavam perguntando-se sobre a forma como iriam trabalhar, o caminho a seguir e o que fazer. Aos poucos, o diálogo foi tomando outros rumos e a interação abriu espaços para a mediação entrar em cena, como se vê a seguir:

Vc sabia que até a roupa é uma tecnologia? Sabe pq usamos roupas? Sabe desde quando utilizamos as vestimentas? O motivo pelo qual usamos roupas não é só pela proteção ou necessidade... mas também pela estética e costumes de cada povo ... (Aluna 33). 
Você acredita que as vestimentas possam ser uma tecnologia? Sabe desde quando utilizamos as vestimentas? (Aluna 41).

Seria bacana colocar a tecnologia da roupa do astronauta e do ciclista, entre outras (Aluna 33).

Meninas, é importante fazer um pequeno texto com todas essas informações para estudarmos e todas ficarem a par de todo o conteúdo (Aluna 09).

Meninas, criei um documento no Google drive para compartilharmos as pesquisas que cada uma fez e as sugestões de cada uma ou se concorda com as opiniões (Aluna 33).

Dessa maneira, as alunas foram colocando no documento algumas imagens, textos e materiais que encontraram em suas pesquisas sobre o tema. Aos poucos, foram empolgando-se com as descobertas, com as aprendizagens. Uma estudante explorou outros materiais para expor, como botões e tecidos raros. Parecia muito empolgada e surpresa. Certo dia postou no grupo uma mensagem:

Meninas, acabei de chegar do centro, fui em uma loja de botões e a mulher me deu uma aula sobre tipos de botões. Gastei um monte em botões, mas amei. Existe botões de vários materiais, tem até de osso.... (Aluna 41).

Esse depoimento deixa claro o envolvimento da estudante com o objeto de investigação: ela se tornou uma pesquisadora que procura informações sobre seu tema de estudo e que compartilha com as colegas suas descobertas, disseminando suas aprendizagens. Isso nos leva a inferir que, quando o aluno se envolve com o objeto de estudo, ele não só aprende, mas partilha com os colegas essa aprendizagem e está em constante atuação.

Nesse trabalho, os estudantes não receberam nada pronto, tudo precisou ser planejado. Cole e Engeström (1993) explicam que a distribuição da cognição humana acontece no meio cultural como consequência de um sistema de práticas que envolve o sujeito, a comunidade, as regras, as mídias, os objetivos e a divisão do trabalho, os quais ocorrem no mundo social e no tempo.

O grupo da linguagem também fez uso do Whatsapp como meio de comunicação, troca de informações sobre o que encontravam e espaço de compartilhamento de material que consideravam útil para a exposição. O trabalho foi realizado com a participação de todos os integrantes, os quais se empenharam na busca por qualidade. A seguir, apresentaremos uma parte da discussão entre os participantes, a qual envolve negociação, interação, diálogo e partilha:

E se a gente fizesse um mapa conceitual para ir organizando conforme as pessoas vão respondendo as questões (Aluna 02).

Isso, a gente poderia colocar vários objetos na mesa e perguntar: qual desses objetos pode ser considerado uma tecnologia? (Aluna 02).

A gente podia colocar cartazes com curiosidades e perguntar: Por que a tecnologia é uma linguagem? (Aluna 32). 
Poderia ser assim: defina o conceito de linguagem como uma tecnologia com uma palavra ou frase ou qual o tipo de linguagem ou expressão de linguagem que você conhece? O que acham? (Aluna 19).

Os estudantes desse grupo fizeram várias pesquisas sobre a linguagem e, tal como os grupos anteriores, produziram um texto no Google drive para a apresentação. Um destaque para esse grupo foi que os integrantes debateram e dialogaram muito sobre as pesquisas nas mídias sociais, leram, partilharam materiais e expressaram ideias relacionadas à leitura nos espaços de interação do grupo. Portanto, as duas ferramentas digitais selecionadas pelos jovens serviram como mediadores na compreensão do conteúdo, porque foram empregadas como espaço de diálogo, de trocas, de compartilhamento e de ajuda mútua na compreensão conceitual.

Sobre isso, vale salientar que é a partir da interação com o outro, por meio da linguagem, das mídias e do trabalho que se efetua um processo de mediação no qual o homem vai desenvolvendo suas funções psicológicas superiores (VIGOTSKI, 2003). Para isso, o autor defende que seu uso “amplia de forma ilimitada a gama de atividades em cujo interior as novas funções psicológicas podem operar” (p. 73).

Essa noção é corroborada por Martins (2015, p. 47), quando afirma que “a mediação é interposição que provoca transformações, encerra a intencionalidade socialmente construída e promove desenvolvimento; enfim, uma condição externa que, internalizada, potencializa o ato de trabalho, seja ele prático ou teórico”.

Do mesmo modo, o grupo que pesquisou sobre as ferramentas valeu-se muito do Whatsapp como mediador na apropriação conceitual. Empolgadas com o trabalho, as alunas trocavam mensagens constantes sobre o que haviam pesquisado e aprendido e solicitavam com frequência o posicionamento das demais colegas em relação ao que estavam pensando e compartilhando. Essa interação foi viabilizada por encontros síncronos e assíncronos organizados pelos próprios estudantes.

Importante realçar que, nos momentos de interação, presencial ou virtual, os jovens contribuíam com seus recursos cognitivos e, com isso, diferentes formas de mediação ocorreram. Para Gomez et al. (2010), as diversas interações sociais que se desenrolam entre os estudantes servem como apoio para o pensamento conceitual.

Moraes e Lima (2019) colaboram nessa reflexão ao acentuar que não se pode pensar no uso das mídias nos espaços educativos como recurso para transmitir conteúdo, mas para "vivenciar experiências didáticas que possibilitem aproveitar ao máximo as potencialidades que tais ferramentas oferecem, para que ele possa aprender ou ampliar as capacidades de explorar, analisar, sintetizar e problematizar”. 
A interação pode ser uma forma de mediação do processo cognitivo dos estudantes em situações nas quais os sujeitos compartilham suas experiências e seus conhecimentos e recebem as contribuições dos demais membros, afetando-se reciprocamente. As práticas de interação podem suceder na relação entre sujeitos e destes com as mídias (SALOMON, 1993), e isso abre alternativas para a distribuição da cognição.

Pudemos perceber que, nos diálogos e nos debates realizados nas mídias digitais, as alunas solicitaram apoio entre si e recorreram ao conhecimento científico como base para a formação conceitual:

Gente, eu vou pesquisar sobre a escova de dente e sobre outras tecnologias. A gente precisa escolher as ferramentas e pesquisar sobre elas pra saber o que falar no dia. Precisamos entender sobre o assunto (Aluna 38).

Nossa, dinheiro é legal, nunca tinha pensado que dinheiro é uma tecnologia. Vou pesquisar sobre isso (Aluna 18).

Para a teoria da cognição distribuída, quando os sujeitos se engajam em um propósito comum, passam a produzir conhecimento socialmente apoiados nas mediações que ocorrem em situações de interação, de diálogo e de colaboração e nas relações que estabelecem com as mídias.

Segundo alguns autores (PEA, 1993; SALOMON, 1993; HERRERO; BROWN, 2010), os momentos de diálogos e de interação que transcorrem quando os sujeitos estão realizando uma tarefa são propícios para a mediação e a distribuição do conhecimento entre os participantes, e, quanto mais participam e envolvem-se, mais esse processo vai intensificando-se. Nesse sentido, as mídias digitais são consideradas um grande diferencial, por proporcionar encontros síncronos e assíncronos e a ampliação da sala de aula para fora dos muros da escola.

À vista disso, a cognição emerge, em diversos contextos, de um conjunto de mediações que acontecem nas relações entre as pessoas com as mídias e com a cultura, constituindo o ambiente em que a cognição se torna, de fato, compartilhada e distribuída (COLE; ENGESTRÖM, 1993).

Os dados expressam que, além de apoderarem-se das mídias digitais como mediadoras na apropriação conceitual, os estudantes também se apropriaram desses dispositivos como ferramenta na construção conjunta de significados. Isso se deu por meio da participação colaborativa, da parceria, da negociação e da ajuda mútua.

Os dados revelam que todos os grupos fizeram uso do editor do Google Drive para a produção de conteúdos e a construção conjunta de significados. Com esse material elaborado, os estudantes produziram vídeos no programa Movie Maker, slides no Power Point e um mapa conceitual no Lucidchart e criaram um blog. 
A parceria intelectual e a participação colaborativa foram vistas nas mais variadas situações e estratégias de trabalho desenvolvidas pelos próprios estudantes para atingir os objetivos propostos. Com isso, entendemos que as práticas de auxílio mútuo têm se tornado parte do contexto dos jovens na realização de suas metas. Herrero e Brown (2010) citam que os processos coletivos desenvolvidos pelos estudantes ampliam as aprendizagens, porque, quanto mais os estudantes interagem, tornam-se parceiros e ajudam-se, mais o conhecimento é mediado e distribuído, e, com isso, todos aprendem e se desenvolvem.

Constatamos a parceria intelectual nos momentos em que houve uma postura de cooperação, no sentido de responsabilizar-se por si e pelo outro, ajudando-se mutuamente na consecução do objetivo e na aprendizagem. De acordo com Salomon (1993, p. 112), “o produto da parceria intelectual que resulta da distribuição de cognições entre indivíduos ou entre indivíduos e artefatos culturais é uma articulação; não pode ser atribuída unicamente a um ou a outro parceiro”. Isso significa que os processos cognitivos se desenvolvem por meio da relação com o outro, com as mídias e com a cultura.

A inter-relação estabelecida em muitos momentos desse trabalho entre os jovens e as mídias converge-se em uma parceria intelectual (SALOMON, 1993). Essa parceria pode, segundo o autor, ajudar no desenvolvimento do pensamento, na construção de novos conhecimentos e no desempenho de tarefas que não seriam viáveis somente com o esforço do humano, sozinho.

A participação colaborativa foi identificada em situações em que as ideias eram partilhadas, discutidas e elaboradas. Como exemplo, podemos citar a situação na qual uma estudante inicia a produção do texto que seria base para a elaboração do vídeo no editor de texto do Google Drive com uma frase e uma imagem e, em seguida, um comentário provoca e estimula a participação dos colegas. Abaixo, alguns excertos desse diálogo:

Podemos colocar mais de uma imagem, dependendo do que abordarmos (Aluna 14).

Seria mais ou menos assim? Uma imagem e a narração em cima? (Aluna 10).

Meninas, escrevi algo que poderíamos narrar... A respeito da parte boa da tecnologia. Seria interessante começar com o lado bom da tecnologia e depois falar do ruim (Aluna 16).

Isso posto, as estudantes produziram um texto no Google Drive que resultou no conteúdo do vídeo com a participação colaborativa de todas. Inicialmente, trouxeram ideias, material selecionado em artigos científicos, perguntas, respostas, inventaram poesias e finalizaram com um texto. Vale mencionar que foi possível perceber, neste caso, que a apropriação das mídias digitais não foi no sentido de amplificar o pensamento, mas de potencializar as capacidades cognitivas. 
Os demais grupos foram pelo mesmo caminho: utilizaram o editor de texto do Google Drive para compartilhar ideias, imagens, textos e materiais que encontraram em suas pesquisas sobre o tema e produzir, de forma colaborativa, conteúdos necessários à exposição. Aos poucos, foram empolgando-se com as descobertas e com as aprendizagens. Isso nos leva a inferir que, quando o aluno participa de forma colaborativa, ele se envolve com o objeto de estudo e não só aprende, mas partilha com os colegas essa aprendizagem, de forma autônoma.

Assim continuaram, cada uma assumindo seu papel na realização das tarefas. A seguir, ressaltamos duas passagens que retratam o trabalho intercorrendo de forma processual e a participação colaborativa ganhando ênfase no texto que estavam produzindo no Google Drive:

Meninas podem colocar aqui as imagens conforme combinamos de como era a roupa na pré-história, antiguidade (Grécia), Idade Média, modernidade contemporaneidade, imagens de como a galera se veste na Índia e em outros países e na hora de explicar a gente fala o pq da diferença das roupas e que estão relacionada a questão cultural e tal, podemos colocar imagens de roupas de astronautas e de ciclistas entre outras que vcs acharem (Aluna 33).

Coloquei o que consegui encontrar, agora só falta neste período a imagem de roupa feita de linho ou qualquer fibra de plantas. Eu li em sites que pelo fato de ser um material que se decompõem muito rápido é difícil encontrá-los (Aluna 09).

Para esse grupo, o editor de texto do Google Drive serviu como espaço de encontro para o planejamento do trabalho a ser apresentado e para a produção do texto que chamaram de "texto base para a apresentação”. As estudantes produziram um vídeo sobre a história da invenção das vestimentas e toda sua trajetória, desde a pré-história até os dias atuais, incluindo a relação com questões sociais e culturais.

Pea (1993, p. 49) alude que "o sentido primário da inteligência distribuída surge do pensamento das pessoas em ação”. Em consonância, Brown et al. (1993, p. 205) explicam que, ao trabalharem em clima de colaboração e de cooperação, os alunos se sentem "encorajados a fornecer feedback uns aos outros, incluindo críticas construtivas e sugestões sobre fontes de informação adicionais”, o que favorece a mediação da aprendizagem.

Assim, de forma colaborativa e participativa, os estudantes pesquisaram, trabalharam, aprenderam e produziram conteúdos. Conforme Brown et al. (1993), o trabalho colaborativo assegura ao grupo um desempenho mais elevado e maduro, ainda que nem todos os membros sejam totalmente capazes de participar de modo efetivo.

Esses dados exprimem que os estudantes lançaram mão da mídia digital para construir significados de maneira coletiva, pois, ao partilhar ideias, planejar, debater, dialogar e produzir 
conteúdos conjuntamente, os dispositivos serviram, de algum modo, como ferramenta para a construção conjunta de significados.

Por meio do diálogo e das interações constantes identificados na mídia digital, notamos que os jovens negociaram a forma de encaminhamento dos estudos, das produções e da apresentação, sem a necessidade de ter alguém supervisionando e cobrando resultados, isto é, trabalharam com liberdade, responsabilidade, autonomia e parceria. Brown et al. (1993) apontam a negociação mútua como um dos conceitos centrais em seu trabalho, sublinhando que, em um ambiente em que se busca a distribuição da cognição, a negociação deve ser uma prática vivenciada constantemente entre os estudantes. Os autores explicitam, ainda, que, ao criar comunidades de aprendizagem em que decorrem constantes negociações e renegociações, os estudantes passam a criar uma base de conhecimento comum e um sistema compartilhado de significados.

Ademais, a diversidade de material que compartilharam nas mídias digitais permitiu uma variabilidade de fundamentos teóricos que subsidiou a produção de conteúdos, o que talvez não ocorresse nos limites impostos em sala de aula. A construção conjunta de significados realizada pelo grupo que construiu um blog com as produções no Google Drive ajuda a ilustrar:

Estou fazendo aquele lance das fotos que a gente tinha falado, lembra? Mas não estou achando minhas anotações, vcs lembram quais a gente selecionou? (Aluna 11).

Acho que podemos fazer postagens intercaladas, tipo: conceituando tecnologia (daí coloco algumas partes dos textos). Algo assim. Estou com umas ideias e depois mando (Aluna 20).

Esse espaço foi utilizado pelas estudantes para organizar e reescrever as ideias e os conceitos, quando necessários, e somente depois os transportar ao blog. Um destaque para o trabalho é que as estudantes tentaram organizar o conteúdo de forma interativa com o leitor, além de começar o trabalho partindo da realidade vivida para então a fundamentar com a teoria. Tal preocupação por parte das estudantes demonstra uma postura diferenciada em relação ao trabalho com o conceito científico. Essa atitude indica um distanciamento da maneira engessada de transmitir uma informação e evidencia que existem outras formas de ensinar e aprender conceitos.

Gomez et al. (2010) argumentam que os alunos podem ser bem-sucedidos quando se tornam aprendizes cognitivos e quando participam de forma colaborativa de atividades significativas com o uso das mídias. Um ponto relevante é que as ferramentas digitais não serviram para fazer as mesmas tarefas que poderiam ser feitas sem elas, ao invés disso, serviram para criar e realizar novas, para estabelecer relações entre os sujeitos, trocas bidirecionais, diálogos e produções, tornando-se, com isso, mediadores do pensamento (SALOMON, 1992). 
Diante de todos os dados aqui relatados, concluímos que a Expotec foi muito significativa para os estudantes, proporcionou experiências e aprendizagens coletivas desde o momento em que nasceu a ideia até a realização do evento e, o mais importante, constituiu-se como um exercício mediador que favoreceu o entrelaçamento entre o teórico e o empírico. Para Martins (2015, p. 50),

o desenvolvimento, a complexificação do pensamento, requer, pois, o estabelecimento de mediações cada vez mais abstratas entre as impressões concretas. Requer o estabelecimento de relações e generalizações entre distintos objetos à vista do ordenamento e sistematização da experiência individual e da imagem subjetiva dela resultante.

A turma precisou planejar e dividir tarefas, assumir responsabilidades múltiplas, enfrentar desafios, produzir material, interagir, negociar, compartilhar e apresentar o trabalho para a comunidade. Nesse sentido, Cole e Engeström (1993, p. 42) postulam que "a cognição distribuída deve ser trabalhada para diferentes tipos de atividade, com suas diferentes formas de mediação, divisão do trabalho, regras sociais, e assim por diante”.

Com isso, entendemos que essa foi uma ação qualitativamente mediadora na formação conceitual que serviu como instrumento dos processos formativos dos estudantes e potencializadora das aprendizagens. No processo de formação de professores, a oportunidade de envolver-se e de participar de maneira mais efetiva e diversificada do que normalmente acontece cotidianamente oportuniza aos estudantes vivências que os ajudam não só a apropriar-se do conceito, mas a entender que ensinar e aprender podem ir além dos formatos institucionalizados.

\section{Considerações Finais}

Neste estudo, os estudantes se apropriaram das mídias digitais como mediadores na apropriação conceitual e como ferramenta na construção conjunta de significados. Os dados sinalizam que as relações e as formas de uso das mídias digitais dão-se em um processo comunitário, exigindo das participantes uma constante negociação, participação e colaboração.

A Expotec foi uma atividade em que os estudantes vivenciaram uma experiência muito diferente de trabalho, de estudo e de aprendizagem, a qual garantiu a motivação necessária para que os alunos se envolvessem com o objeto de conhecimento, assumissem a responsabilidade na apropriação do conceito e na construção conjunta de significados. Tal performance ainda conduziu à prática de interação, de colaboração e à parceria como estratégia de mediação, favorecendo novas atuações em relação às formas de produção de conhecimento, consolidando-se como uma situação desafiadora, capaz de operar a serviço do desenvolvimento dos estudantes. 
Os jovens apropriaram-se das mídias para produzir e transmitir informações, compartilhar conhecimentos, fazer sínteses, mediar e regular os processos cognitivos, ampliando as noções de espaço e de tempo. Com isso, entendemos que essas ferramentas possibilitam a simultaneidade não apenas das ações, mas também do pensamento. Por conseguinte, o trabalho se tornou processual e proporcionou uma forma de interação contínua, estimulou e intensificou a participação espontânea dos jovens e a regulação do pensamento na elaboração conceitual e na produção de conteúdos. O resultado foi a compreensão de uma cultura de colaboração, de interação e de mediação que passou a fazer parte daquele contexto. Ao trabalharem juntos, precisaram negociar, argumentar e defender as compreensões conceituais que estavam em níveis distintos, o que encaminhou para a reorganização e a apropriação conceitual.

A chance de realizar um trabalho variado, capaz de ultrapassar a ideia de aprender de forma individual e mecânica para depois reproduzir na prova, mudou o curso das ações dos sujeitos ao transformarem o trabalho de compreensão conceitual e de produção de conteúdos em momentos de aprendizagem e ao apropriarem-se das mídias digitais para mediar as funções cognitivas e as atividades práticas.

Consideramos isso como um ganho aos processos formativos dos estudantes, pois, segundo Coll e Monereo (2010) o potencial transformador dessas ferramentas concretiza-se quando forem capazes de "mediar as relações entre os participantes - especialmente entre os estudantes, mas também os professores - e os conteúdos de aprendizagem” (p. 76) e quando servirem para "mediar as interações, as trocas comunicacionais entre os participantes, seja entre professores e estudantes e entre os próprios estudantes” (p. 76).

Além disso, concluímos que a natureza do exercício proposto permitiu que as apropriações das mídias digitais se voltassem para práticas como o confronto cognitivo, o diálogo, o compartilhamento de ideias e de materiais, a interação recíproca, a participação colaborativa, a parceria intelectual e a elaboração de sínteses. As laborações mediadoras propiciaram a construção ativa do sujeito, via internalização dos conteúdos externos em conteúdos da consciência, favorecendo a ampliação-das capacidades psíquicas (VIGOTSKI, 2001).

Nesse sentido, concordamos com o autor ao dizer que o meio é o fator determinante do desenvolvimento dos processos mentais e, para tanto, defendemos a necessidade de experiências formativas em que as mídias digitais sejam utilizadas como elementos mediadores das ações dos estudantes, a fim de assegurar que estes se apropriem de tais ferramentas como reguladoras do pensamento em seus processos formativos. 
Diante disso, compreendemos que, quando as mídias forem utilizadas nessa perspectiva, poderão servir para fazer generalizações, promover formas de representação conceitual, orientar e regular o pensamento, podendo ser consideradas, então, como mediadoras do pensamento e favorecedoras da formação conceitual e do desenvolvimento dos sujeitos.

\section{Referências}

BARDIN, Laurence. Análise de conteúdo. Lisboa: Edições 70, 1997.

BROWN, Ann Leslie et al. Distributed expertise in the classroom. In: SALOMON, Gavriel Distributed cognitions: psychological and educational considerations. Cambridge: CUP, 1993. p. 188-228.

CASTELLS, Manuel. A galáxia da internet: reflexões sobre a internet, os negócios e a sociedade. Rio de Janeiro: Jorge Zahar, 2003.

COLL, Cesar; MONEREO, Carles (orgs.). Psicologia da educação virtual: aprender e ensinar com as tecnologias da informação e da comunicação. Porto Alegre: Artmed, 2010.

CGI. Comitê Gestor da Internet no Brasil. TIC Domicílios 2019. 2020. Disponível em: https://www.cetic.br/pt/noticia/tres-em-cada-quatro-brasileiros-ja-utilizam-a-internet-apontapesquisa-tic-domicilios-2019/. Acesso em: 06 nov. 2019.

COLE, Michael; ENGESTRÖM, Yrjö. A cultural-historical approach to distributed cognition. In: SALOMON, G. Distributed cognitions: psychological and educational considerations. Cambridge: CUP, 1993. p. 01-46.

GOMEZ, Mary Louise et al. Technology, learning and instruction: distributed cognition in the secondary english classroom. Literacy, v. 44, n. 1, p. 20-27, abr. 2010.

HERRERO, Carlos; BROWN, Maria. Distributed cognition in community-based education. Revista de Psicodidáctica, v. 15, n. 2, p. 253-268, 2010.

HUTCHINS, Edwin. Cognition in the wild. Cambridge: MIT Press, 1995.

KARASAVVIDIS, Ilias. Distributed cognition and educational practice. Journal of Interactive Learning Research, Creta, v. 13, p. 11-29, 2002.

LANGE, Patricia G.; ITO, MIzuko. Creative Production. In: ITO, Mizuko et al. Hanging out, messing around and geeking out: kids living and learning whit new media. Massachusetts: MIT Press, 2010. p. 243-337. Disponível em: https://llk.media.mit.edu/courses/readings/Ito_HangingOut_Intro_Ch1.pdf. Acesso em: 12 dez. 2019.

MARTINS, Lígia Márcia. A internalização de signos como intermediação entre a psicologia histórico-cultural e a pedagogia histórico-crítica. Germinal: Marxismo e Educação em Debate, v. 7, n. 1 , p. 44-57, jun. 2015.4 Disponível em: https://portalseer.ufba.br/index.php/revistagerminal/article/view/12291. Acesso em: 12 dez. 2019.

MORAES, Dirce Aparecida F. de; LIMA, Claudia Maria de. Os artefatos digitais como ferramentas culturais mediadoras: possibilidades para novos cenários de aprendizagem. Educar em Revista, v. 35, n. 78, p. 243-262, dez. 2019. Disponível em: https://revistas.ufpr.br/educar/article/view/59642. Acesso em: 03. jan. 2020. 
PEA, Roy D. Practices of distributed intelligence and designs for education. In: SALOMON, G. Distributed cognitions: psychological and educational considerations. Cambridge: CUP, 1993. p. 47-87.

ROCHA, Marisa Lopes da; AGUIAR, Katia. Faria de. Pesquisa-intervenção e a produção de novas análises. Psicologia: Ciência e Profissão, Brasília, n. 4, p. 64-73, 2003. Disponível em: http://pepsic.bvsalud.org/pdf/pcp/v23n4/v23n4a10.pdf. Acesso em: 08 dez. 2019.

SALOMON, Gavriel. Distributed cognitions: psychological and educational considerations. Cambridge: CUP, 1993.

SALOMON, Gavriel. Las diversas influencias de la tecnología em el desarrollo de la mente. Journal: Infancia y Aprendizaje, v. 15, n. 58, p. 143-159, jan. 1992.

SALOMON, Gavriel; PERKINS, David; GLOBERSON, Tamar. Partners in cognition: extending human intelligence with intelligent technologies. Educational Researcher, v. 20, p. 2-9, 1991.

VIGOTSKI, Lev Semenovich. A formação social da mente. São Paulo: Martins Fontes, 2003.

VIGOTSKI, Lev Semenovich. Obras escogidas. Madrid: Visor Distribuidores, 2001.

Recebido em: 20/05/2020

Aprovado em: 08/12/2020 